Journal of Teacher Education for Sustainability, vol. 22, no. 2, pp. 90-103, 2020

\title{
Learnings from the \#IndigenousESD Global Research: Twenty-First Century Competencies for All Learners
}

\author{
Katrin Kohl and Charles A. Hopkins \\ York University, Toronto, Canada
}

\begin{abstract}
The 2030 Agenda for Sustainable Development promotes with the Sustainable Development Goal 4 a quality education for all and aims to ensure equal access to all levels of education and vocational training for vulnerable groups, such as Indigenous Peoples. However, most education systems are not yet in a position to embrace a culturally appropriate way of teaching children and youth of their Indigenous communities. The \#IndigenousESD research creates a voice for relevant education stakeholder groups, including Indigenous Elders/leaders, ministry officials, parents, students, and teachers from communities with Indigenous students on their perceptions of quality education.

Based on a participatory research approach developed together with Indigenous communities and researchers from around the world, dialogues held in 54 research settings in 26 countries show a focus on the acquisition of twenty-first century competencies for learners amongst the most important aspects of a quality education.

For this article, the authors focused on knowledge, attitudes and skills, providing recommendations for policy makers in education to better address the needs and priorities of Indigenous communities. Findings from the research indicate that teaching twentyfirst century competencies are at the center of concern in all stakeholder groups, yet want these competencies taught in a context to which Indigenous students can readily relate. Adjusting the pedagogy of delivering these common competencies in the classroom could be an important step towards a feasible and affordable path within existing education systems to better serve Indigenous students and all learners.
\end{abstract}

Key words: Indigenous ESD Global Research, competencies, twenty-first century learners

\section{Introduction}

The global research project Reorienting Education and Training Systems to Improve the Lives of Indigenous Youth aims to improve the lives of Indigenous youth, in or from traditional communities by enhancing the quality of their education. The research follows a community-based participatory research approach. The unique approach of this research on how education outcomes for Indigenous youth can be improved is by engaging education for sustainable development (ESD), i.e., addressing local social, economic and environmental issues and designing appropriate pedagogy. York University in Toronto, 
Canada leads and coordinates the project by involving more than 120 (research) institutions and communities having schools with Indigenous students in approximately 40 countries/Indigenous peoples' territories.

The research was designed to serve the 2030 Agenda with the Sustainable Development Goals (SDGs) (United Nations, 2015), in particular UNESCO’s SDG 4 mandate with the Global Education 2030 Agenda (UNESCO, 2015a). By establishing this project for one of the least served groups (May \& Aikman, 2010) after successful research in high-scoring PISA countries (Laurie et al., 2016), the first international research on SDG Target 4.5 was launched with the possibility for research institutions to collaborate beyond this initial research project.

Interested research institutions were required to fulfil certain criteria to be considered for participation. The criteria for institutional membership included:

- Eligible research institutions were (accredited) teacher education institutions or institutions of higher education as they collected the data and oversaw the actual research and its reporting.

- If the coordinating research institution was not an institution of higher education, it was expected to work in close collaboration with such an institution, e.g., by signing an underlying Memorandum of Understanding or other form of agreement.

- The research was expected to be conducted in cooperation with a coordinating Indigenous organization or other suitable institution.

- Principal and coordinating researchers were expected to hold a minimum of a Bachelor's degree, to have a basic knowledge and understanding of the SDGs and ESD as well as communication skills in English.

- Access to necessary (human and fiscal) resources to carry out the research plan.

The criteria for eligibility of an Indigenous partner site included:

- The school had the support of the school leaders and staff.

- The school had the permission and ability to modify the curriculum.

- Where possible, the school/community had the approval of the ministry of education or the local tribal council or overall education authority and had to work in close collaboration with those authorities.

- Access should exist to necessary (human and fiscal) resources to support carrying out the research plan.

The research project, under patronage by UNESCO-UNEVOC and the Canadian Commission for UNESCO, was financed through private donations. While researchers work directly under the respective and appropriate cultural and ethical regulations with schools and community leaders, their research covers three research initiatives:

1. Quality Education Dialogue: Exploring the various perspectives on quality education and its desired outcomes as seen by ministries of education, Indigenous community leaders, principals and teaching staff, parents, students and other stakeholders;

2. Best practices: Collecting examples of "Good Practice using ESD” in delivering quality education for Indigenous youth; and

3. Action research: Performing action research in exploring ESD approaches to improve the overall quality of education for Indigenous youth based on how quality education is perceived by stakeholders as found in research initiative 1 . 
An initial global research report covered an extensive data analysis from the first research initiative covering 29 countries in all UN regions (Kohl \& Hopkins, 2020) with concrete policy recommendations to assist UNESCO, education and community leaders worldwide to reorient existing education systems towards sustainability regarding the following aspects: program coordination and curriculum; information sharing and learning; resource mobilization, networks; as well as planning, monitoring and reporting mechanisms and suggestions to enhance the implementation of SDG 4.

This in-depth analysis focuses on twenty-first century learning competencies as the issue with the highest priority based on the findings of the research.

\section{Education for Sustainable Development and the 2030 Agenda}

Education for Sustainable Development as a concept does have a long history in the sustainability movement going back to the Agenda 21 when sustainable development in its three dimensions (economic, environmental and social) was first recognized as a concept and education was seen as a central means of implementing a sustainable future (United Nations, 1987; United Nations, 1992). Ever since, there have been tremendous efforts to reorient the world towards sustainability with the focus on ESD (McKeown \& Hopkins, 2006; McKeown \& Hopkins, 2010; Heasly et al., 2020).

The 2030 Agenda for Sustainable Development (United Nations, 2015) with its 17 SDGs addressing the most pressing world challenges, adapted in content and pedagogy to a local context and addressed within its education system, is one of the key thrusts of ESD (Hopkins \& McKeown, 2001; UNESCO, 2012). A crucial intent of the reorienting is to address the understandings and worldviews inherent within sustainable development to make the curriculum relevant and culturally appropriate (UNESCO, 2017a).

SDG 4 and Education 2030 (UNESCO, 2015a) define the Global Education 2030 Agenda Goal: Ensure inclusive and equitable quality education and promote lifelong learning opportunities for all (United Nations, 2015, p. 14) with a target - SDG 4.5 - addressing opportunities for vulnerable groups, amongst them Indigenous Peoples, who are still excluded from access to education in many cases (United Nations, 2015, p. 17).

Aiming at embedding ESD at all levels of education as a purpose of education (UNESCO, 2014), the United Nations General Assembly reiterated in 2019 (after the first call in 2017) ESD ... as a vital means of implementation for sustainable development (...) and as an integral element of the Sustainable Development Goal on quality education and a key enabler of all the other Sustainable Development Goals (United Nations, 2017, p. 3; United Nations, 2019, p. 4).

\section{Indigenous Peoples in the 2030 Agenda}

This research recognizes the lack of a definition of Indigenous Peoples in the United Nations system (UNDESA, 2008) as using a universal normative definition of this particular often marginalized group facing considerable limitations (Bowen, 2000; Kenrick \& Lewis, 2004; May \& Aikman, 2010). The project addressed Indigenous youth, including those who continue to live in, or have recently left traditional cultures. In the spirit of the 2030 Agenda, the Principal Researchers have used the term in a respectful and appropriate attempt of engaging and learning both with and from Indigenous Peoples. 
Although Indigenous Peoples have been granted full human rights (United Nations, 2007) helping them to get many Indigenous issues recognized although not all solved (Champagne, 2013), still today and with few exceptions, youth, in or from traditional cultures, remain amongst the least-well served by their respective public education and training systems with some of the lowest graduation rates from elementary, secondary or tertiary education. Indigenous girls are more likely to be affected (UNESCO, 2016).

There is a significant lack of understanding of why Indigenous students often do not function well in most education systems (e.g., Gray \& Hunter, 2000; Song et al., 2014). The social and economic disparities that arise from an inequitable education system are considerable (UNESCO, 2017b). Yet, little research-based knowledge is available to effectively address the situation.

\section{Quality Education Dialogue: Overall Methodology and Data Collection}

\section{Phase 1: Creating the report template for research initiative 1}

As a joint basis to carry out the dialogue for this research, a model to structure and document the conversation in each community was needed. It was meant to generate comparable findings from around the world on the research initiative What are desirable education outcomes as perceived by relevant stakeholders that define the quality of education for Indigenous youth?

The overall research methodology (Kohl \& Hopkins, 2020) was based on models used to describe UNESCO's humanistic approach to learning: The Faure Report (1972), the Delors Report (1996) and Rethinking Education (2015), added by the three dimensions of sustainable development (economic, environmental and social). Scholars emphasize Delors' relevance widely to date and even identify five pillars in the same model to highlight its potential for transformation adding "learning to transform oneself and society" (Power et al., 2007; Biasutti et al., 2016).

Researchers were invited to use the provided model to facilitate the dialogue. Yet, building on the experience from action research for sustainability (Salite et al., 2009) researchers were free to decide how to carry out the actual dialogue in their community with the involvement of the Indigenous communities themselves engaged in all steps along the way.

While this approach allowed for participation of diverse groups from several countries, various approaches and different ways of conducting the conversation, language translation barriers and the inability to control the community conversation resulted in a lack of in-depth reporting aligned with the template, collectively posed limitations to this research.

Phase 2: Carrying out the quality education dialogue and documenting the results

Researchers facilitated the \#IndigenousESD quality education dialogue accordingly and with local adaptation to match legal and cultural appropriateness (Kohl \& Hopkins, 2020). 
Phase 3: Categorizing and understanding the results, creating the global research overview

The results from all research settings were systematically examined (Kohl/Hopkins, 2020) based on the framework of the UNESCO Policy on engaging with Indigenous Peoples (UNESCO, 2018) and in accordance with the United Nations Declaration on the Rights of Indigenous Peoples (UNDRIP) 2007 (United Nations, 2007) in the following dimensions of the UNESCO Policy:

1. Human rights and fundamental freedoms, health;

2. Equality and non-discrimination;

3. Self-determination, participation, leadership;

4. Cultural heritage, knowledge, traditional cultural expressions and languages;

5. Development with culture and identity;

6. Conservation and protection of environment; and

7. Gender equality.

Since 2019 was declared the International Year of Indigenous Languages (United Nations, 2016), a special priority was given to Indigenous languages and qualified as a subcategory of cultural heritage according to Article 11 UNDRIP. Also, health and leadership were expected from the discussions in planning meetings to be important subcategories of their respective UNDRIP category. Items were categorized in several rounds of individual and collective examinations; an item could be applied to several categories when appropriate.

64 research institutions were actively involved with the research network and report data for this global initiative were received from 54 institutions:

- Asia-Pacific region: 24 institutions from 9 countries/territories (Australia, China, India, Malaysia, Maldives, New Zealand, Philippines, Austronesian Taiwanese);

- Central Asian region: 4 institutions from 3 countries (Kazakhstan, Russia, Tajikistan);

- Central/North American region: 9 institutions from 3 countries (Canada, Nicaragua, USA);

- Europe: 1 institution (Finland);

- South American region: 5 institutions from 5 countries (Bolivia, Brazil, Chile, Peru, Venezuela);

- Southern African region: 3 institutions from 3 countries (Botswana, Lesotho, South Africa);

- Sub-Saharan Africa: 8 institutions from 2 countries (Ethiopia, Nigeria).

\section{Overall Research Findings from the Application of the Delors-based Model}

The findings from all UN regions allowed for the examination of 578 items that had been applied to the Delors-based model. Categorizing the items led to the following regional distribution with 1,011 matches within the ten categories (Figure 1).

Participating stakeholders could be identified from the following groups: Community, Indigenous Peoples (including Elders), ministry officials, parents, students, and teachers. The groupings of $41 \%$ of all respondents who participated in the discussions were not further defined by the research teams (Figure 2). 


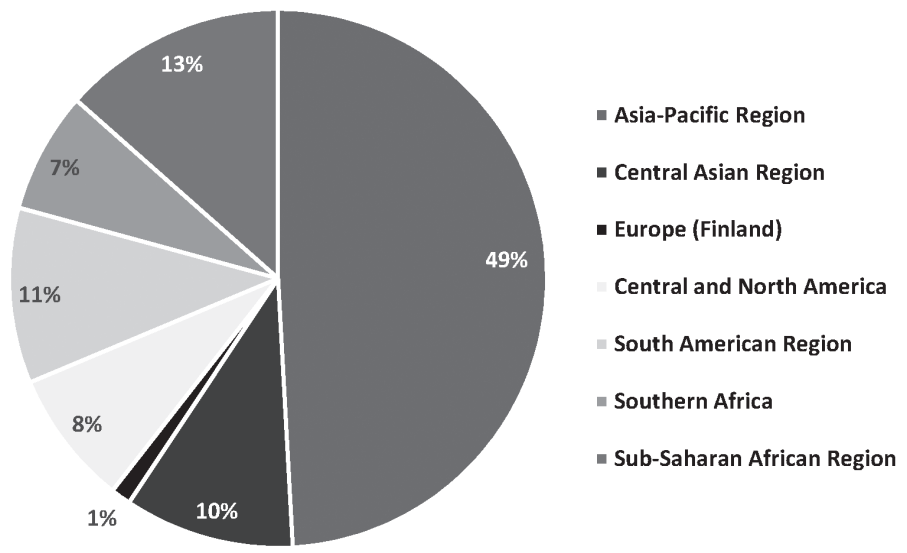

Figure 1. Regional distribution of total research findings

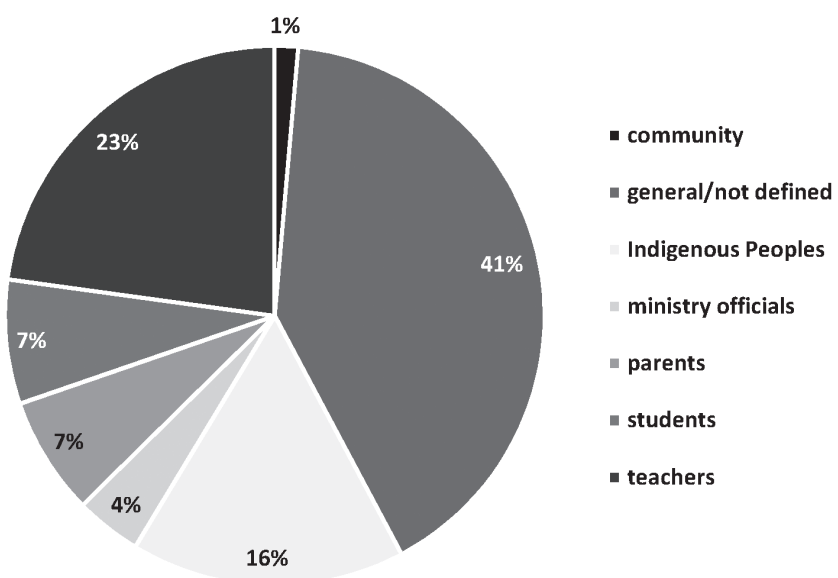

Figure 2. Total research findings coming from various stakeholders

The 578 ESD items were also classified according to dimensions of sustainable development (environmental, social and economic) in the data collection process at each research setting when possible.

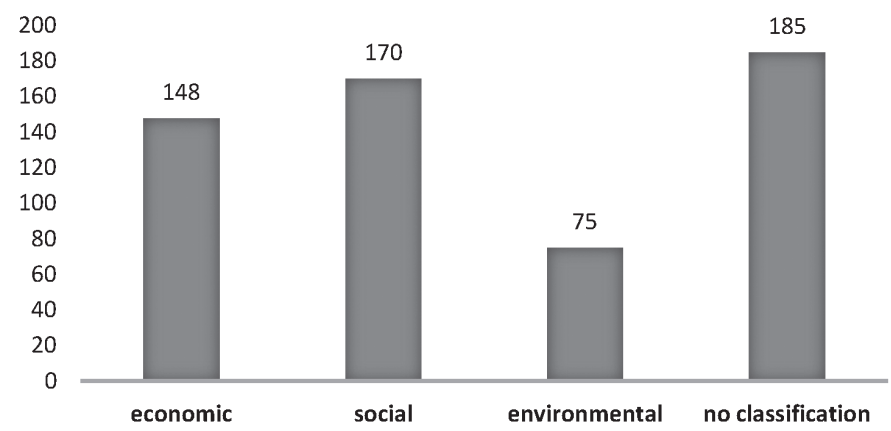

Figure 3. Research items categorized according to the three dimensions of sustainable development 


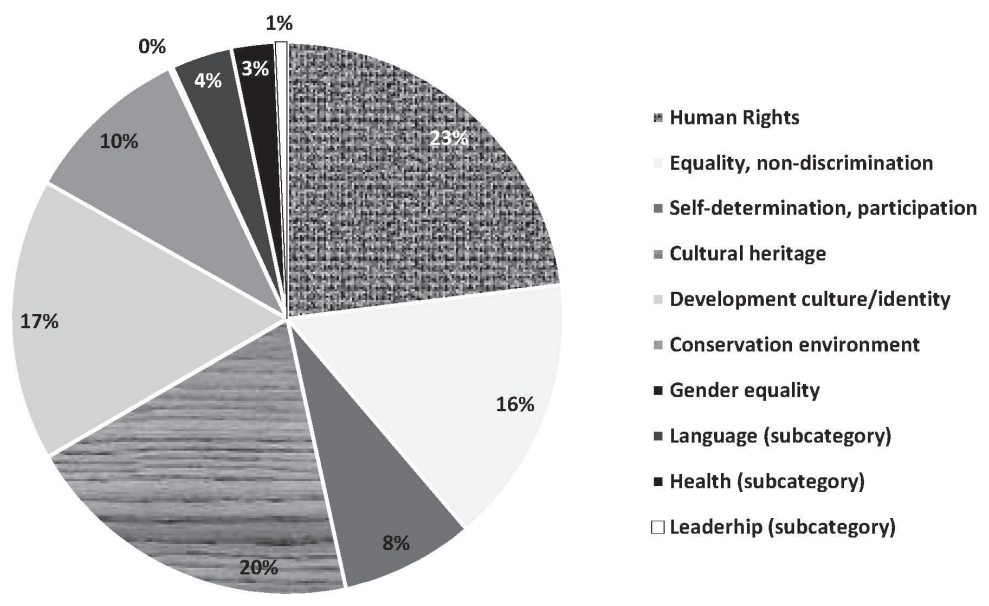

Figure 4. Total average results per UNDRIP-based category from all regions

All regions demonstrated a particular composition of responses matching the UNDRIP-based categories. The following charts demonstrate the percentage of responses targeting competencies (in \% from 100 overall regional responses) for each of the regions in the research.

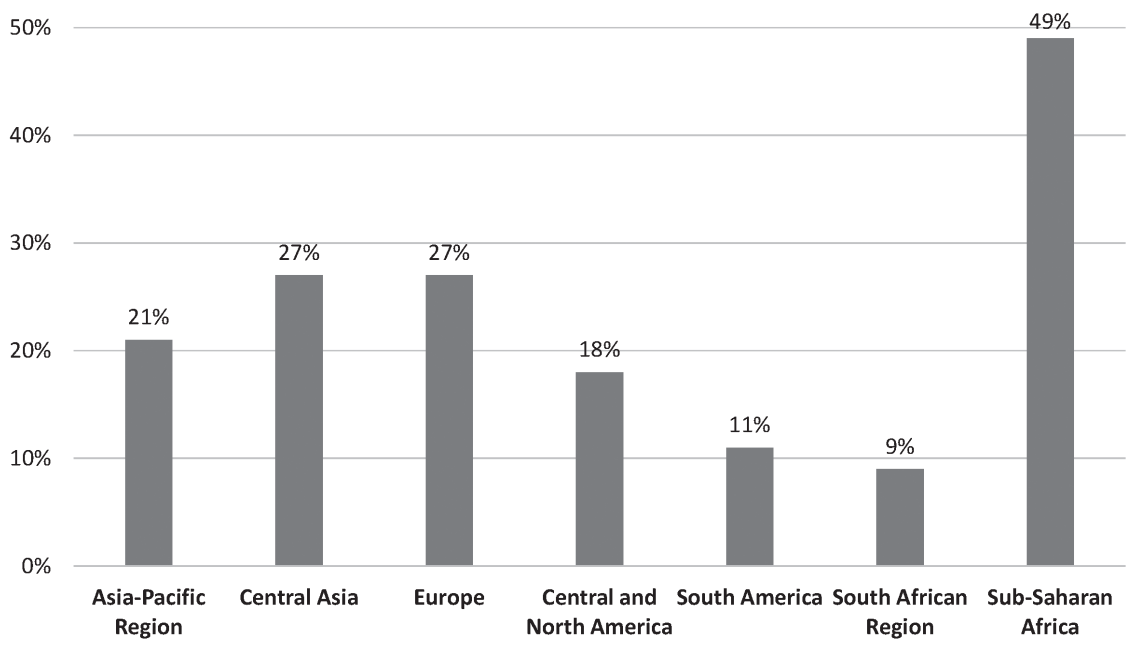

Figure 5. Distribution of regional responses for the UNDRIP-based category 'Human rights, fundamental freedoms with a specific focus on twenty-first century competencies'

\section{Findings on Human Rights, Fundamental Freedoms with a Specific Focus on Twenty-First Century Competencies}

Responses to the category of human rights occurred not only quantitatively often but also qualitatively in most regions where the quality education dialogue was held with education stakeholders (23\% of overall responses). While the category covered a broader context, most respondents mentioned the acquisition and understanding of 
various mainstream competencies (knowledge, skills and attitudes) common globally to students in schools (Bell, 2016). This access to excellent education was seen as a human right for (Indigenous) students. Each region put a different emphasis on this category. The access and retention in education providing the opportunity to acquire what is commonly called twenty-first century knowledge and skills was of utmost importance in the Sub-Saharan African region (49\% of regional responses), followed by Finland (27\%) and Central Asia (27 \%). It was also seen relevant in the Asia-Pacific Region (21\%) and the Central and North American regions (18\%). The results from the South American region (11\%) and South African Region (9\%) showed less importance for this category.

Stakeholder groups in all regions seem to be extremely concerned about Indigenous children often not succeeding within existing education systems. All stakeholder groups acknowledged the need for access to education and acquiring competencies. The dialogue results also showed that stakeholders were not against mainstream education but rather worried about children's success within the system. No stakeholder group advocated for a separation of Indigenous students from other student groups but rather inclusion with respect for Indigenous culture and heritage.

Analyzing each stakeholder group, participants gave different importance to the human rights category. Most groups emphasized the importance of knowledge, skills and attitudes in a quality education as one of the highest priorities. Especially the overall communities (47\% of responses), ministry officials (28\%) followed by teachers, students and parents particularly appreciated elements of twenty-first century competencies.

Another aspect was the concern for appropriateness of teachers to teach Indigenous youth and the need for in-service training. To meet expectations, teachers need to update their knowledge and skills regularly (e.g., acquiring the language skills to be able to teach subjects, such as history, science and maths, in the English language).

Competencies suggested by various stakeholders in the regions were broad and often not further prioritized. Fortunate for education systems, what stakeholder groups wish students to gain is overlapping with mainstream twenty-first century competencies, such as suggested by UNESCO named key competencies for sustainability (UNESCO, 2017; Rieckmann, 2012; Scott, 2015c) or OECD’s Learning Framework 2030 (OECD, 2018).

The following examples show broad responses from various regions and research settings:

- Asia-Pacific - Malaysia: Introduce $21^{\text {st }}$ century learning techniques to realize benefits from modern knowledge and preservation of traditional knowledge, and to also use appropriate learning approaches that Orang Asli (Indigenous Peoples) best respond to (stakeholder not defined);

- Asia-Pacific - Malaysia: Graduates should know both traditional and contemporary (formal) knowledge (parent);

- Asia-Pacific - Philippines: Training of teachers in Indigenous Peoples Education (Indigenous Peoples);

- Asia-Pacific - New Zealand: Students shall be skilled to understand the world, also an inconsistent world (teacher);

- Asia-Pacific-Maldives: Know how to use computer technology, using media and technology, students should be aware of the latest technology (stakeholder not defined); 
- Central Asia - Kazakhstan: Schools are introducing a new education system. Many subjects at senior courses must be in English. But there are no educators who will teach subjects in English in rural schools. Teachers who know English go to work in the city (teacher and ministry);

- South America - Peru: Acquiring literacy skill (stakeholder not defined);

- Southern Africa - Botswana: Learn about their history and stories of their community (stakeholder not defined);

- Sub-Saharan Africa - Nigeria: Any education that makes me better than my parent is quality. I am more excited when I am using my hand and my head to do something. So quality education should be the one that uses what I like to teach me what I need (students);

- North America-Canada: To ensure that these learners have the tools to gain academic and economic success and remain in their community if they choose, with the understanding that Anishinaabe and Western knowledge imparts not only understanding but also responsibility to work for the greater good (student);

- Sub-Saharan Africa - Nigeria: The school is trying but they should do more by getting quality teachers not adhoc teachers like Youth corpers that do not have the needed commitment most of the times. They should get seasoned and experienced teachers (Community).

\section{Recognizing the Relevance of Twenty-First Century Competencies for All Learners}

\section{Context for Policy Recommendations}

The research is designed and carried out to serve UN/UNESCO, education leaders and Indigenous communities globally with evidence-based policy recommendation. Therefore, the following recommendations focus on existing education systems and highlight the need for structural changes for both Indigenous youth and possibly all other learners.

\section{Overview of Policy Recommendations from this Research}

Based on the evidence from the quality education dialogue, the following 10 policy recommendations for education systems that serve students in and from traditional communities were developed (for detail on the overall recommendations from this research: Kohl \& Hopkins, 2020):

- Teach twenty-first century competencies in locally relevant and culturally aligned contexts;

- Systematically strengthen technical and vocational training on all levels of education;

- Include Indigenous Elders and the local community in the learning process;

- Intensify engagement of Indigenous students in youth-appropriate settings;

- Communicate on online platforms with other students, schools and communities that will develop media literacy and provide joint learning for all learners;

- Engage teacher education institutions to work closely with local Indigenous communities in addressing locally relevant sustainability issues; 
- Address teaching certification to allow Indigenous knowledge keepers to teach Indigenous perspectives;

- Provide information on and foster access to (inter)national school networks and other education networks;

- Strengthen cooperation of ministries of education with Indigenous Elders and with other key stakeholders; and

- Ensure participation of stakeholders in education management.

\section{Focus on Twenty-First Century Learners' Competencies}

Teaching twenty-first century competencies is not the only but the first and at the heart of all of these recommendations. The full text of the first recommendation reads as follows:

Teaching twenty-first century competencies in locally relevant and culturally aligned contexts means to prepare all learners for a changing world dealing with major challenges in climate and environment, digitalization and artificial intelligence, globalization, migration and urbanization that will allow all Indigenous children to thrive in the mainstream school system and to succeed in both worlds.

All stakeholders in all regions acknowledge the need for and are concerned about access to and retention in quality education for Indigenous youth. Living in "two worlds" and needing knowledge, skills and attitudes to manage the requirements of thriving in both - often fundamentally different - environments and cultures are inherent across all stakeholder responses from all regions. The general perception is that Indigenous students have to manage greater amounts and various dimensions of knowledge and skills to be able to succeed.

Therefore, Indigenous knowledge and perspectives should not only be part of their education to ensure success in later life in that world but also to make education relevant for the Indigenous students while they are in schooling. It was inferred that the respectful inclusion of Indigenous knowledge and perspectives will support them in developing their future identities as Indigenous. If education builds on Indigenous students' informal knowledge from their upbringing in Indigenous communities, new innovative pedagogy in connecting those dots should be possible. This would ensure a more seamless and comprehensive education rather than parallel learning in and about two different worlds. Consequently, students could become viable, responsible citizens, proud of their heritage, connected spiritually to the land, and yet attain well-being, meaningfulness, and manage the requirements of the workplace in whatever setting they choose to live in, including modern urban societies.

Many of the worldviews that Indigenous Peoples wish to protect and nurture, are closely aligned with the mainstream education approaches to sustainable development through both Education for Sustainable Development and Global Citizenship Education $(G C E D)$. With the hope for all learners to strive for sustainable development, a concept that reflects much commonly found in Indigenous worldviews, all learners could benefit by acquiring twenty-first century knowledge, skills and perspectives from traditional worldviews in a societal pursuit of a sustainable future. 
As sustainable development is an overarching goal to be pursued by all of humanity as evidenced by the global adoption of the 2030 Agenda for Sustainable Development and the Global Education 2030 Agenda, it is most appropriate to reciprocally share perspectives, insights into ecological knowledge and worldviews. The proposed perspective of seeing the quest for sustainability as an inherent purpose of quality education by mainstream education systems should prove to be a significant facilitator of addressing the current misalignment of education outcomes for Indigenous students. Reinforcing and acknowledging abilities to see value in Indigenous cultures' traditional knowledge, skills and worldviews while acquiring twenty-first century competencies would strengthen Indigenous students' learning. Respectfully combining Indigenous knowledge, skills, values, perspectives and worldviews while investigating current and future environmental, social and economic issues as a curricular vehicle to address twenty-first century competencies would be of benefit to all learners.

To successfully adapt, alterations of both content and pedagogy will have to be made. Adaptations to current teacher competencies should not be overlooked. Nor should assessment tools and expected outcomes. It is helpful that the demand for twentyfirst century competencies for all learners allows building on what is currently being implemented in most education systems (UNESCO, 2017a). Many education systems and international comparative tools (e.g., PISA) have moved from a focus on content knowledge towards competence-oriented curricula and student assessment.

Changes made to correct the current inequities would likely benefit all students and societies in general as profound changes are deemed necessary to address the issues delineated in the 2030 Agenda. Teaching for future well-being, both individual and societal, could include how previous cultures dealt with uncertainty, including their treatment of the planet and all life forms. While considerable adaptation would be needed, curricular and pedagogical issues are currently expected, regularly reviewed and modified as a systemic ongoing part of education processes. This is not a reversal of current thrusts but rather the simple inclusion of a major need within current strategic endeavors that would be of benefit of all.

\section{Conclusion}

The \#IndigenousESD research demonstrates that there is interest by stakeholders and an opportunity in the movement towards the 2030 Agenda to significantly improve education outcomes for Indigenous students. This research has also been a unique opportunity to create a dialogue on equal footing among various stakeholder groups and anecdotal evidence shows that the conversation supported relationship building in various communities, such as in the Philippines, where researchers went beyond the quality education dialogue and developed an ongoing support system for an Indigenous community in health, farming and education. It once more shows that it is of relevance to build the relationship among officials, communities, teachers, parents and students to listen to one another and consider each other's perspectives to determine and create a path towards the best possible outcomes for Indigenous students. Implementing changes based on the policy recommendations informed by this research into perceptions of education quality, especially teaching twenty-first century competencies in a context to which Indigenous students can relate, would create a feasible and affordable path within existing education systems to better serve Indigenous students. When properly acknowledging and serving 
the aspects of a quality education as perceived by Indigenous students and their community, including traditional knowledge, and respectfully seeking Indigenous perspectives in classroom discussions, student engagement could be enhanced enabling all learners to better achieve academically. Thus, societal inclusivity could be strengthened, alternative sustainable futures explored and hopefully created.

\section{References}

Biasutti, M., De Baz, T., \& Alshawa, H. (2016). Assessing the infusion of sustainability principles into university Curricula. Journal of Teacher Education for Sustainability, 21-40. Retrieved from https://doi.org/10.1515/jtes-2016-0012

Bowen, J. (2000). Should we have a universal concept of 'Indigenous Peoples' rights'?: Ethnicity and essentialism in the twenty-first century. Anthropology Today, 16(4), 12-16. Retrieved from http://www.jstor.org/stable/2678305

Champagne, D. (2013). UNDRIP (United Nations Declaration on the Rights of Indigenous Peoples). Human, civil, and indigenous rights. Wicazo Sa Review, 28(1), 922. Retrieved from https://www.muse.jhu.edu/article/506184

Delors, J. et al. (1996). Learning: The treasure within - Report to UNESCO of the International Commission on Education for the Twenty-first Century. Paris: UNESCO. Retrieved from https://unesdoc.unesco.org/ark:/48223/pf0000109590

Department of Economic and Social Affairs of the United Nations Secretariat (UNDESA). (2008). Resource Kit on Indigenous Peoples. New York: United Nations. Retrieved from https://www.un.org/esa/socdev/unpfii/documents/resource_kit_indigenous_ 2008.pdf

Faure (1972). Faure, E., Herrera, F., Kaddoura, A., Lopes, H., Petrovsky, A. V., Rahnema, M., \& Ward, F. C. Learning to be. The world of education today and tomorrow. Paris: UNESCO. Retrieved from https://unesdoc.unesco.org/ark:/48223/pf0000001801

Gray, M. C., Hunter, B., \& Schwab, R. G. (2000). Trends in indigenous educational participation and attainment, 1986-96. Australian Journal of Education, 44(2), 101-117. Retrieved from https://doi.org/10.1177/000494410004400202

Heasly, B., Iliško, Dz., Salìte, I., \& Lindner, J. (2020). The value of process and pedagogy through the sustainability prism. Discourse and Communication for Sustainable Education, 11(2), 1-4.

Hopkins, C., \& Kohl, K. (2019). Teacher education around the world: ESD at the heart of education - responsibilities and opportunities towards a sustainable future for all. In Karrow, D., \& DiGiuseppe, M. (Eds.), Environmental and sustainability education: Canadian perspectives. Cham $(\mathrm{CH})$ : Springer Nature AG.

Hopkins, C., \& McKeown, R. (2001). Education for sustainable development: Past experience, present action and future prospects. Educational Philosophy and Theory, 33(2), 231-244. Retrieved from https://doi.org/10.1111/j.1469-5812.2001.tb00265.x

Kenrick, J., \& Lewis, J. (2004). Indigenous peoples' rights and the politics of the term 'indigenous'. Anthropology Today, 20(2), 4-9. Retrieved from https://doi.org/ 10.1111/j.0268-540X.2004.00256.x

Kohl, K., \& Hopkins, C. (2020). ESD FOR ALL: Learnings from the \#IndigenousESD global research. Journal of Teacher Education for Sustainability, 21(2), 105-120. Retrieved from https://doi.org/10.2478/jtes-2019-0020 
Laurie, R., Nonoyama-Tarumi, Y., McKeown, R., \& Hopkins, C. (2016). Contributions of Education for Sustainable Development (ESD) to quality education: A synthesis of research. Journal of Education for Sustainable Development, 10(2), 1-17. Retrieved from https://doi.org/10.1177/0973408216661442

May, S., \& Aikman, S. (2003). Indigenous education: Addressing current issues and developments. Comparative Education, 39(2), 139-145. Retrieved from https://doi.org/10.1080/03050060302549

McKeown, R., \& Hopkins, C. (2006). EE and ESD: Two paradigms, one crucial goal. Applied Environmental Education \& Communication, 4(3), 221-224. Retrieved from https://doi.org/10.1080/15330150591004616

McKeown, R., \& Hopkins, C. (2010). EE p ESD: Defusing the worry. Environmental Education Research, 9:1, 117-128. Retrieved from https://doi.org/10.1080/ 13504620303469

Organisation for Economic Co-operation and Development (OECD). (2018). The future of education and skills. Education 2030. Paris: OECD. Retrieved from https://www. oecd.org/education/2030/E2030\%20Position\%20Paper\%20(05.04. 2018).pdf

Power, A., Southbell, B., \& Elliot, R. (2007). Teacher education for the future: Some Australian perspectives. Journal of Teacher Education for Sustainability, 27-39. Retrieved from https://doi.org/10.2478/v10099-009-0003-8

Rieckmann, M. (2012). Future-oriented higher education: Which key competencies should be fostered through university teaching and learning? Futures, 44(2), 127135. Retrieved from https://doi.org/10.1016/j.futures.2011.09.005

Salīte, I., Gedžūne, G., \& Gedžūne, I. (2009). Educational action research for sustainability: Seeking wisdom of insight in teacher education. Journal of Teacher Education for Sustainability, 11(2), 14-30. Retrieved from https://doi.org/10.2478/v10099009-0037-y

Scott, C. L. (2015c). Education research and foresight. The futures of learning 2: What kind of learning for the $21^{\text {st }}$ century? UNESCO Working Papers. Retrieved from https://unesdoc.unesco.org/ark:/48223/pf0000242996

Song, S., Perry, L. B., \& McConney, A. (2014). Explaining the achievement gap between Indigenous and non-Indigenous students: An analysis of PISA 2009 results for Australia and New Zealand. Educational Research and Evaluation, 20:3, 178198. Retrieved from https://doi.org/10.1080/13803611.2014.892432

United Nations Conference on Environment and Development. (1992). Earth summit, Agenda 21. Retrieved from http://www.un-documents.net/agenda21.htm

United Nations Educational, Scientific and Cultural Organization (UNESCO). (2012). Education for sustainable development. Sourcebook. Paris: UNESCO. Retrieved from https://sustainabledevelopment.un.org/content/documents/926unesco9.pdf

United Nations Educational, Scientific and Cultural Organization. (2014). UNESCO world conference on education for sustainable development, Aichi-Nagoya, Japan, 2014: Aichi-Nagoya Declaration on Education for Sustainable Development. Retrieved from https://unesdoc.unesco.org/ark:/48223/pf0000231074

United Nations Educational, Scientific and Cultural Organization. (2015a). Education 2030 - incheon declaration and framework for action for the implementation of Sustainable Development Goal 4. Paris: UNESCO. Retrieved from http://uis.unesco. org/sites/default/files/documents/education-2030-incheon-framework-for-actionimplementation-of-sdg4-2016-en_2.pdf 
United Nations Educational, Scientific and Cultural Organization. (2015b). UNESCO rethinking education. Towards a global common good? Paris: UNESCO. Retrieved from https://unesdoc.unesco.org/ark:/48223/pf0000232555

United Nations Educational, Scientific and Cultural Organization. (2016). UNESCO global education monitoring report 2016: Education for people and planet: Creating sustainable futures for all. Paris: UNESCO. Retrieved from https://unesdoc.unesco. org/ark:/48223/pf0000245752

United Nations Educational, Scientific and Cultural Organization. (2017a). Education for sustainable development goals: Learning objectives. Paris: UNESCO. Retrieved from https://unesdoc.unesco.org/ark:/48223/pf0000247444

United Nations Educational, Scientific and Cultural Organization. (2017b). UNESCO global education monitoring report 2017/2018: Accountability in education: Meeting our commitments. Paris: UNESCO. Retrieved from https://unesdoc.unesco. org/ark:/48223/pf0000259338

United Nations Educational, Scientific and Cultural Organization. (2018). UNESCO policy on engaging with Indigenous peoples. Paris: UNESCO. Retrieved from https://unesdoc. unesco.org/ark:/48223/pf0000262748

United Nations Educational, Scientific and Cultural Organization. (2019). The future of education initiative. Retrieved from https:/en.unesco.org/futuresofeducation/

United Nations General Assembly. (1987). Development and international co-operation: Environment report of the world commission on environment and development. Annex. Report of the world commission on environment and development. Our common future. Released by the Brundtland Commission. Retrieved from https://sustainabledevelopment.un.org/content/documents/5987our-commonfuture.pdf

United Nations General Assembly. (2007). United Nations Declaration on the Rights of Indigenous Peoples (UNDRIP). New York: United Nations. Retrieved from https://www.un.org/development/desa/indigenouspeoples/wp-content/uploads/sites/ 19/2018/11/UNDRIP_E_web.pdf

United Nations General Assembly. (2015).Transforming our world: The 2030 Agenda for sustainable development. New York: United Nations. Retrieved from https://www.un.org/ga/search/view_doc.asp?symbol=A/RES/70/1\&Lang=E

United Nations General Assembly. (2016). Rights of Indigenous peoples. Retrieved from https://undocs.org/en/A/RES/71/178

United Nations General Assembly. (2017). Education for sustainable development in the framework of the 2030 Agenda for sustainable development. Retrieved from https://digitallibrary.un.org/record/1318978

United Nations General Assembly. (2019). Education for sustainable development in the framework of the 2030 Agenda for sustainable development. Retrieved from https://undocs.org/en/A/74/381/Add.8

Correspondence concerning this paper should be addressed to Katrin Kohl, York University Toronto, Faculty of Education. Email: kkohl@edu.yorku.ca 